\title{
The growth rate and clinical outcomes of radiation induced meningioma undergoing treatment or active monitoring
}

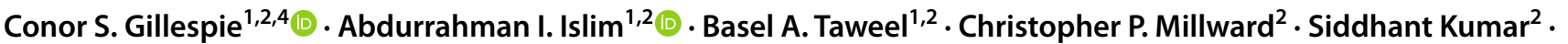 \\ Nitika Rathi ${ }^{2}$ - Shaveta Mehta ${ }^{3}$ - Brian J. Haylock ${ }^{3}$ - Nicola Thorp ${ }^{3}$. Catherine E. Gilkes ${ }^{2}$. David D. A. Lawson ${ }^{2}$. \\ Samantha J. Mills ${ }^{2} \cdot$ Emmanuel Chavredakis $^{2}$. Jibril Osman Farah ${ }^{2} \cdot$ Andrew R. Brodbelt ${ }^{2} \cdot$ Michael D. Jenkinson $^{1,2}$ (D)
}

Received: 14 March 2021 / Accepted: 15 April 2021 / Published online: 22 April 2021

(c) The Author(s) 2021

\begin{abstract}
Introduction Radiation induced meningioma (RIM) incidence is increasing in line with improved childhood cancer survival. No optimal management strategy consensus exists. This study aimed to delineate meningioma growth rates from tumor discovery and correlate with clinical outcomes.

Methods Retrospective study of patients with a RIM, managed at a specialist tertiary neuroscience center (2007-2019). Tumor volume was measured from diagnosis and at subsequent interval scans. Meningioma growth rate was determined using a linear mixed-effects model. Clinical outcomes were correlated with growth rates accounting for imaging and clinical prognostic factors.

Results Fifty-four patients (110 meningiomas) were included. Median duration of follow-up was 74 months (interquartile range [IQR], 41-102 months). Mean radiation dose was $41 \mathrm{~Gy}$ (standard deviation $[\mathrm{SD}]=14.9$ ) with a latency period of 34.4 years $(\mathrm{SD}=13.7)$. Median absolute growth rate was $0.62 \mathrm{~cm}^{3} /$ year and the median relative growth rate was $72 \% / y e a r$. Forty meningiomas (between 27 patients) underwent surgical intervention after a median follow-up duration of 4 months (IQR 2-35). Operated RIMs were clinically aggressive, likely to be WHO grade 2 at first resection (43.6\%) and to progress after surgery (41\%). Median time to progression was 28 months (IQR 13-60.5). A larger meningioma at discovery was associated with growth (HR 1.2 [95\% CI 1.0-1.5], $P=0.039$ ) but not progression after surgery (HR 2.2 [95\% CI 0.7-6.6], $P=0.181$ ). Twenty-seven (50\%) patients had multiple meningiomas by the end of the study.

Conclusion RIMs exhibit high absolute and relative growth rates after discovery. Surgery is recommended for symptomatic or rapidly growing meningiomas only. Recurrence risk after surgery is high.
\end{abstract}

Keywords Meningioma $\cdot$ Radiation $\cdot$ Volumetric growth $\cdot$ Natural history $\cdot$ Radiation induced meningioma

\section{Introduction}

Conor S. Gillespie and Abdurrahman I. Islim are joint first author.

Conor S. Gillespie

hlcgill2@liv.ac.uk

1 Institute of Systems, Molecular and Integrative Biology, University of Liverpool, Liverpool, UK

2 The Walton Centre NHS Foundation Trust, Liverpool, UK

3 Clatterbridge Cancer Centre NHS Foundation Trust, Liverpool, UK

4 School of Medicine, University of Liverpool, Cedar House, Ashton Street, Liverpool L69 3GE, UK
Radiation induced meningioma (RIM) is defined as a meningioma occurring secondary to radiation treatment that satisfies specific criteria relating to: location of radiation, differing histology from previous malignancy, and at least a 5-year interval period after radiation treatment [1-4]. Meningiomas are the most common type of brain tumor to occur following cranio-spinal radiotherapy [5], with a one in eight risk of developing a RIM by the age of 40 [6-8]. Improvements in childhood and adult cancer survival rates have led to an increased incidence of RIM. The management strategy for these patients is an important clinical problem [9].

RIMs are more clinically aggressive than sporadic meningioma, likely to be multiple and recur after surgery [10]. 
No reported studies have examined the growth rate and outcomes of untreated RIM. MRI screening for late intracranial effects of childhood radiotherapy, including the development of meningioma, is a common clinical practice [11, 12]. Volumetric growth patterns of RIM and the subsequent optimal management of asymptomatic cases remains unclear-a fact highlighted as a physician-reported barrier to screening by $74 \%$ of responders in a recent international survey [11].

Volumetric studies of meningioma growth are lacking in general, with many focussing on growth following surgical management [13-17]. A volumetric study conducted from diagnosis will be more relevant for both the patient and clinician, particularly as there are increasing numbers of patients with 'incidental' meningiomas undergoing active monitoring $[18,19]$.

\section{Objective}

To investigate the volumetric growth rates, prognostic factors and outcomes of treated and untreated radiation-induced meningiomas.

\section{Methods}

\section{Study design, setting and participants}

Between 1st January 2007 and 31st March 2019, a single center, retrospective cohort study was performed. The study was approved by the hospital audit committee. Adults $>16$ years diagnosed with a meningioma who had received cranial radiation treatment $>5$ years before discovery/presentation were eligible for inclusion. Patients with syndromic meningiomas were excluded. The study setting was a tertiary neuroscience center, where a formal screening program for late effects of radiation is not in place. Patients were identified either incidentally or through symptomatic presentation.

\section{Baseline characteristics}

Baseline clinical characteristics included indication for prior radiation therapy, radiation dose and fractionation, latency period (time in years from cranial radiation to first MRI diagnosis of RIM), presenting symptoms (defined as symptomatic if presenting with clinical signs or symptoms attributable to meningioma), age at meningioma diagnosis and sex. Imaging features were single or multiple meningioma, location as per the International Consortium on Meningioma classification [18], volume and signal intensity on T2 MRI (hypo/iso/hyper). Tumor volume was calculated according to the $A B C / 2$ formula on contrast-enhanced T1- weighted
MRI/CT $(A=$ maximum meningioma diameter on axial plane, $B=$ diameter perpendicular to $A$, and $C=$ maximum height on coronal or sagittal plane). Each tumor was measured 3 times and the mean used to calculate the tumor volume. Dural tails were not included in volume calculation. Inter and intra-rater reliability of meningioma volume was assessed on a random sample of 24 patients (sample size determined using the Bland equation [20]) by 2 observers independently (CSG and BAT) using the intraclass correlation coefficient (ICC).

\section{Management data}

Management decision at diagnosis was stratified into active monitoring or intervention (surgery or radiation therapy). For patients placed under active monitoring, follow-up intervals, tumor volume on each scan and neurological status were recorded, until intervention or end of study period. Surgical outcomes included extent of resection (complete [Simpson grade 1-3] or subtotal [Simpson grade 4-5]), and WHO grade.

\section{Study endpoints}

\section{Primary endpoint}

The study primary endpoint was volumetric meningioma growth (absolute growth rate (AGR) $\geq 2 \mathrm{~cm}^{3} /$ year or AGR $\geq 1 \mathrm{~cm}^{3} /$ year and relative growth rate $(\mathrm{RGR}) \geq 30 \%$ ). Three MRI scans, and a minimum of 5 months follow-up, were required for a patient to be included in this analysis.

\section{Secondary endpoints}

Secondary endpoints were treatment (surgery, radiotherapy or stereotactic radiosurgery [SRS]), progression following treatment, development of new meningiomas (multiplicity) and mortality.

\section{Statistical analysis}

\section{Volumetric growth rate}

Meningioma growth rate was determined using a longitudinal linear mixed-effect regression model for meningioma volume with time as the fixed variable and included both the random intercept and slope. Absolute growth rate (AGR) was defined as the increase in volume per year in cubic centimeters. Relative growth rate (RGR) was defined as percentage increase in volume per year. 


\section{Prognostic analyses}

The Chi-square test was used to examine statistical differences in outcomes for categorical variables. The Student t-test, Mann-Whitney U test or Kruskal Wallis test were used to examine continuous variables as appropriate. Correlation between baseline variables was evaluated using the Pearson correlation coefficient. Prognostic factors for the study endpoints were delineated using stepwise multivariate proportional hazard regression analysis, incorporating variables with $P$-values $\leq 0.1$ on univariate analysis. Data analysis was conducted using R V4.0.2 and SPSS V25 (IBM, Armonk, NY, USA).

\section{Results}

\section{Baseline, clinical and radiological features}

After excluding two patients with a familial syndrome (Neurofibromatosis type 1 and Gorlin-Chaudhary Moss syndrome) 54 patients with a total of 110 intracranial meningiomas were included. Of these, 18 patients with 37 tumors did not have sufficient radiological follow up, and were excluded from the volumetric component of the study. The baseline, clinical and radiological characteristics are shown in Table 1.

The most common indications for primary radiation treatment were medulloblastoma $(18.5 \%, \mathrm{n}=10 / 54)$, pilocytic astrocytoma $(13 \%, \mathrm{n}=7 / 54)$, and leukemias $(26 \%, \mathrm{n}=14 / 54)$ (Table 1). Median age at time of radiation treatment (RT) for primary pathology was 9.4 years (range 1.7-59.9 years). Of 52 patients with age at radiation available, 28 were under 10 years of age (53.8\%), 14 were between 10 and 19 (26.9\%), and 10 patients were over 19 years of age (19.2\%).

Out of 54 patients, 28 were diagnosed incidentally, and 26 were symptomatic. Forty-four patients had a single meningioma at discovery, and 10 patients had multiple meningiomas ( 24 between them). The mean tumor volume at diagnosis was $4.9 \mathrm{~cm}^{3}(\mathrm{SD}=11.8)$ with no statistical difference in mean volume between meningiomas discovered incidentally compared to symptomatically $(P=0.351)$. Inter- and intra-rater reliability were adequate (Online supplementary table S1).

\section{Radiotherapy received at first diagnosis}

The radiotherapy dose and fractionation regimes were variable (Online supplementary table S2). No radiotherapy data was available for $37 \%$ of patients, most frequently because patients had received radiotherapy at another oncology center. The prescribed radiotherapy dose was in the range $18 \mathrm{~Gy}$ to $55 \mathrm{~Gy}$ at doses per fraction of $1.67 \mathrm{~Gy}$ to $2.4 \mathrm{~Gy}$.
Lower doses were used in patients treated for acute lymphoblastic leukemia on historical protocols receiving prophylactic cranial irradiation. Medulloblastoma and germinomas were treated in 2 phases with an intermediate dose to the whole craniospinal axis followed by a boost giving a higher dose to the tumor bed. Focal higher doses were employed for low grade glioma and craniopharyngioma. No correlation was observed between radiation dose and latency period (Pearson correlation coefficient $=-0.355, P=0.055)$.

\section{Management plans and outcomes}

The management and outcome for patients is shown in Fig. 1. The overall median follow-up period was 74 months after diagnosis (IQR 41-102 months) and twenty-seven patients had surgery for at least one meningioma during the follow up period $(n=27 / 54,50 \%)$, with $36.4 \%$ of all RIMs undergoing surgery $(n=40 / 110)$. Among those operated, median time from first scan to operation was 4 months (IQR 2-35).

\section{Active monitoring}

Thirty-eight patients commenced active monitoring initially (70.4\%) (Fig. 1). Median duration of active monitoring was 64.5 months (IQR 24.8-105.8). The median number of scans for each patient was 7 (IQR 4-10). Almost all patients were followed up with 6 monthly or annual contrast enhanced T1- weighted MRI scans. One patient was followed up using $\mathrm{CT}$ scans due to having a ferromagnetic surgical clip from previous surgery. Overall, 24 patients developed multiple or additional meningiomas during follow up (44.4\%). The median time to discovery of a second or further multiple meningiomas was 53.7 months from time of diagnosis (IQR 25.8-69.3). Of the discovered RIMs, 43 (39.1\%) underwent intervention eventually (surgery, $\mathrm{n}=40, \mathrm{SRS}, \mathrm{n}=2$ and $f \mathrm{RT}$, $\mathrm{n}=1)$. The indications for intervention were patient preference $(n=3,7.0 \%)$, radiological growth $(n=27,62.8 \%)$ and development of symptoms $(n=13,30.2 \%)$. Symptoms were headaches $(n=6)$, seizures $(n=2)$, limb weakness $(n=2)$, limb sensory change $(n=1)$, expressive dysphasia $(n=1)$ and ataxia $(n=1)$. The median time to surgery from diagnosis was 4 months (IQR 2.0-35.0).

\section{Intervention results}

Of tumors with Simpson grade available $(\mathrm{n}=38)$, the rate of complete surgical resection was $97.4 \%$ (Simpson grade 1, $\mathrm{n}=23$, Simpson grade 2, $\mathrm{n}=13$ and Simpson grade 3, $\mathrm{n}=1$ ). One patient had a Simpson grade 4 resection. Meningiomas were WHO grade 1 (56.4\%), and WHO grade $2(43.6 \%)$ at the time of first operation with no correlation observed with radiation dose (Kruskal Wallis test, $P=0.700$ ). Eleven 
Table 1 Patient characteristics for 54 patients with 110 Radiation induced meningioma

\begin{tabular}{|c|c|}
\hline Baseline characteristics & Value \\
\hline Total patients & 54 \\
\hline Total meningiomas & 110 \\
\hline Single $(\%)$ & $44(81.5)$ \\
\hline Multiple (\%) & $10(18.5)$ \\
\hline Male $(\%)$ & $30(55.6)$ \\
\hline Female $(\%)$ & $24(44.4)$ \\
\hline Median age at discovery (range) & $44.5(18-82)$ \\
\hline Mean latency period (SD) & $34.4(13.7)$ \\
\hline Female, n (\%) & $24(44.4)$ \\
\hline Median age at radiation (IQR) & $9.4(1.7-59.9)$ \\
\hline Mean radiation dose (SD) & $41.01(15.0)$ \\
\hline Fractionations (SD) & $20.9(10.2)$ \\
\hline Symptoms & Frequency $(\%)$ \\
\hline Yes & $26(48.1)$ \\
\hline No & $28(51.9)$ \\
\hline Headache/raised ICP & $13(50.0)$ \\
\hline Cranial nerve deficit & $7(26.9)$ \\
\hline Seizures/epilepsy & $3(11.5)$ \\
\hline Enlarging mass & $1(3.8)$ \\
\hline Other & $2(7.6)$ \\
\hline Reason for prior radiation treatment & Frequency $(\%)$ \\
\hline Medulloblastoma & $10(18.5)$ \\
\hline Pilocytic astrocytoma & $7(13.0)$ \\
\hline Acute lymphoblastic leukaemia (ALL) & $7(13.0)$ \\
\hline Other/unknown leukaemia & $7(13.0)$ \\
\hline Other/unknown & $23(42.6)$ \\
\hline Meningioma laterality & Frequency $(\%)$ \\
\hline Right sided & $46(44.2)$ \\
\hline Left sided & $47(45.2)$ \\
\hline Central & $10(10.6)$ \\
\hline ICOM location & Frequency $(\%)$ \\
\hline Convexity & $52(47.3)$ \\
\hline Parafalcine & $16(14.5)$ \\
\hline Sphenoid wing & $10(9.1)$ \\
\hline Posterior fossa- lateral and posterior & $9(8.2)$ \\
\hline Anterior midline & $7(6.4)$ \\
\hline Parasagittal & $7(6.3)$ \\
\hline Tentorial & $5(4.5)$ \\
\hline Intraventricular & $1(0.9)$ \\
\hline Intraosseous & $1(0.9)$ \\
\hline Signal intensity & Frequency $(\%)$ \\
\hline Isointense & $56(50.9)$ \\
\hline Hypointense & $7(6.4)$ \\
\hline Hyperintense & $27(24.5)$ \\
\hline
\end{tabular}

ICOM International Consortium on Meningioma, ICP intracranial pressure 


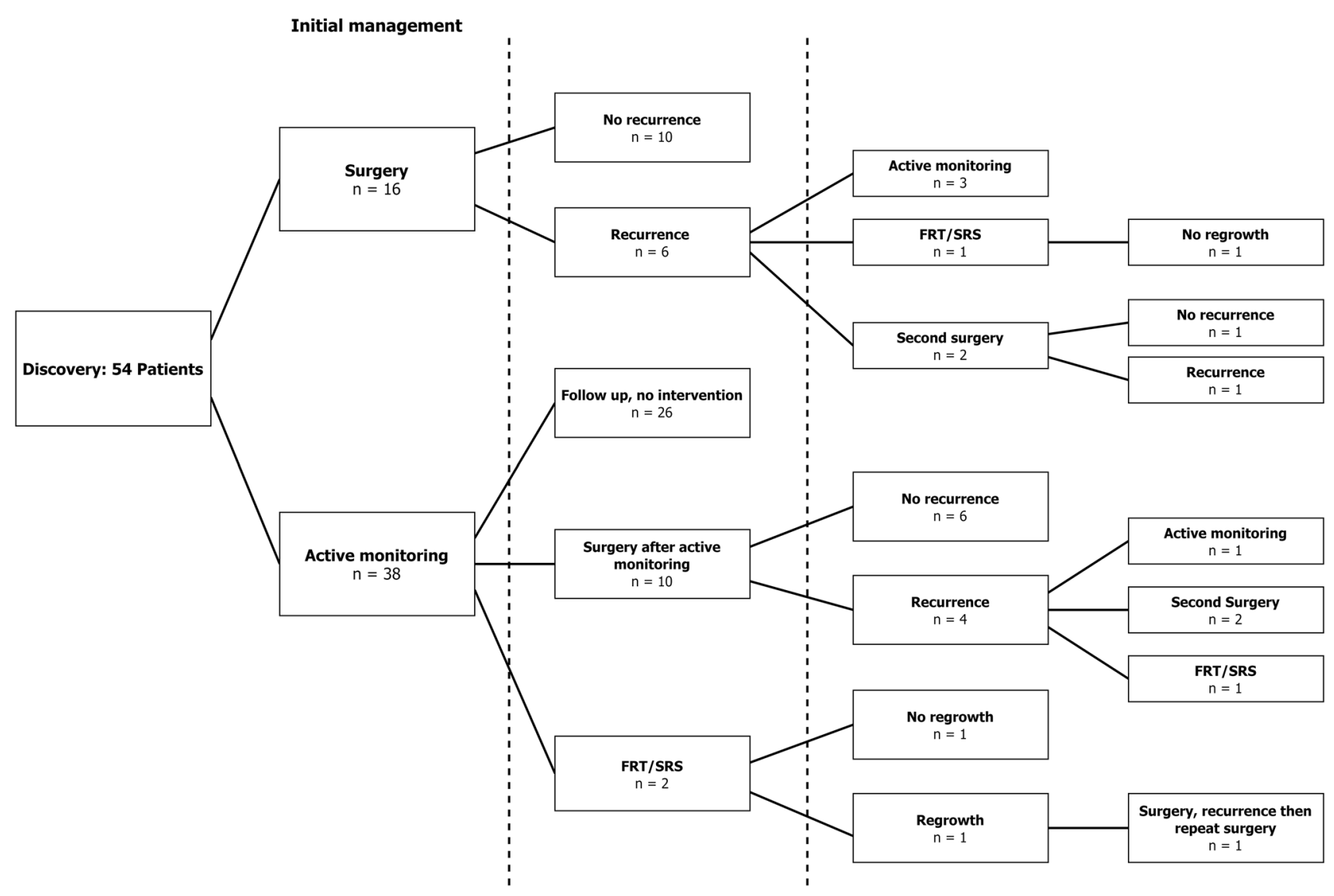

Fig. 1 Patient management showing treatment strategy after diagnosis and subsequent management. RIM radiation induced meningioma, FRT fractionated radiotherapy, $S R S$ stereotactic radiosurgery

patients progressed (42.3\%); 7 were diagnosed on scheduled MRI follow-up and 4 patients had new headache symptoms that prompted an earlier MRI scan. The median time to progression was 28 months (IQR 13-60.5 months). Five patients underwent a second operation for tumor progression. In all re-operated patients, complete surgical resection was achieved and the pathology revealed WHO grade $2(n=3)$, WHO grade $1(n=1)$ and WHO grade $3(n=1)$ meningiomas. Radiation treatment (SRS and $f \mathrm{RT}$ ) was administered after a period of active monitoring $(n=3)$, and following progression after surgery $(n=2)$. One patient who underwent SRS continued to demonstrate evidence of meningioma growth, required two operations, and demonstrated malignant transformation from $\mathrm{WHO}$ grade 2 to $\mathrm{WHO}$ grade 3 at last operation.

\section{Growth characteristics}

The growth rates are shown in Fig. 2. 39.7\% of meningiomas with more than 5 months of clinical follow up demonstrated volumetric growth during the study period $(n=29 / 73)$. How this compares to non-RIM tumor growth in other studies is shown in Table 2.

The median absolute growth was $2.1 \mathrm{~cm}^{3}$ (IQR 0.8-8.1), and the median absolute growth rate was $0.62 \mathrm{~cm}^{3}$ per year (IQR 0.24-2.29). The median relative growth rate (RGR) was $246 \%$ (IQR 113-586\%), and the median relative volume growth per year was 72\% (IQR 29-245\%). The overall median tumor doubling time (TDT) was 918 days.

Meningiomas that had surgical intervention grew at a significantly faster rate (median TDT 544 days vs 2301 days, $P<0.001)$ and meningiomas that were asymptomatic grew at a slower rate (median TDT 1921 days vs 1104 days), although this was not statistically significant $(P=0.506)$. Of the operated meningiomas, there was a difference between the doubling times of WHO grade 1 and WHO grade 2 tumors (median TDT 460 days vs 280 days respectively), however this was not statistically significant $(P=0.395)$.

\section{Prognostic factors for study outcomes}

Median meningioma growth free survival was 56 months (95\% CI 41-91). Median intervention free survival was 

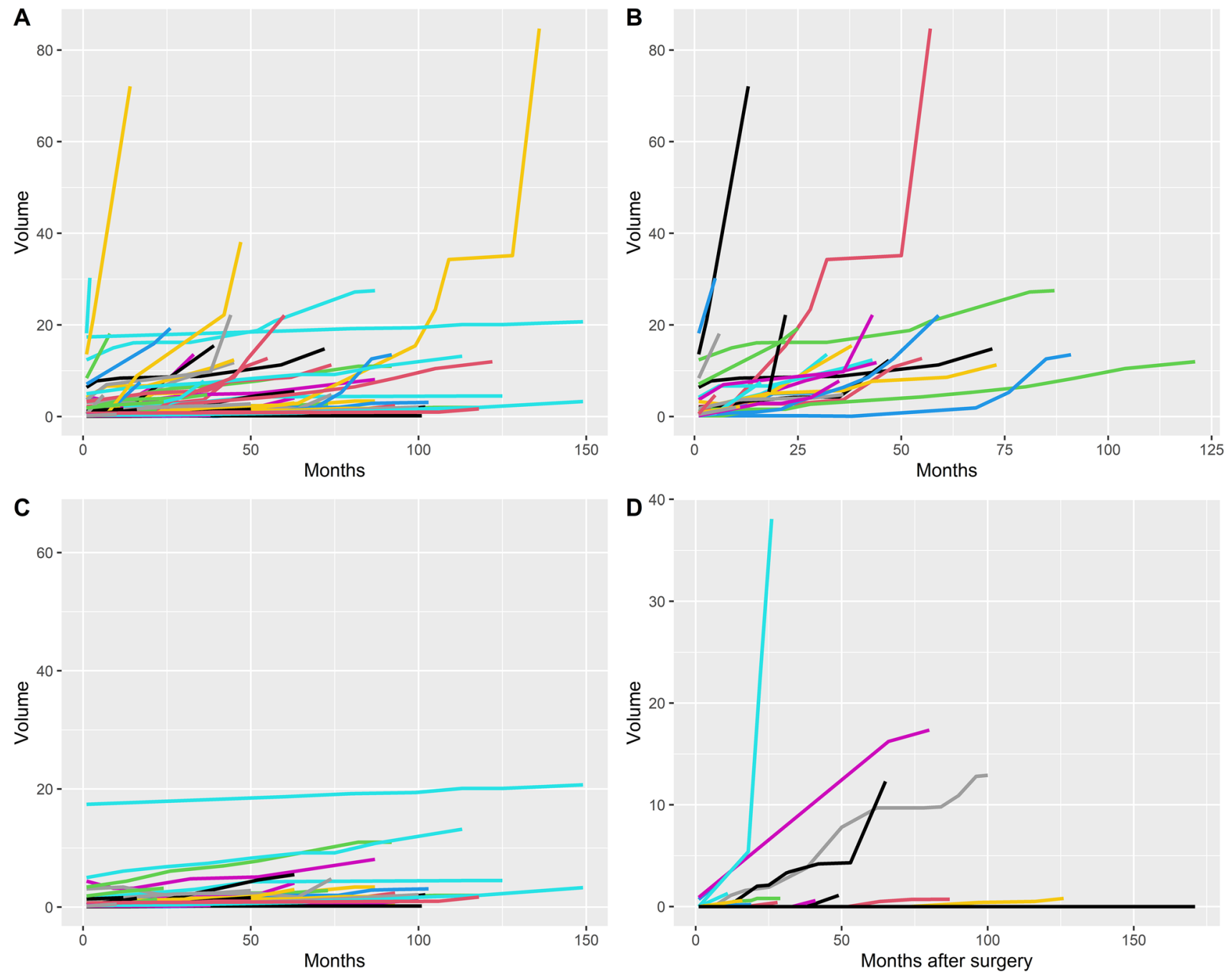

Fig. 2 Volume time plots demonstrating. a All RIM patients with volumetric analysis. b Growth plots of RIMs that met standard growth definition of AGR $\geq 2 \mathrm{~cm}^{3} /$ year or AGR $\geq 1 \mathrm{~cm}^{3} /$ year and $\mathrm{RGR} \geq 30 \%$

per year. c Growth plots of RIMs that did not grow during the study period and $\mathbf{d}$ meningioma growth after surgery

40 months (95\% CI 5-NA). Median progression free survival after surgery was 78 months (95\% CI 38-NA), and the median multiplicity free survival was 69 months after diagnosis (95\% CI 42.6-NA) (Fig. 3).

Prognostic factors for tumor growth, surgery and recurrence are shown in online supplementary material tables S3-S7. Tumors that demonstrated 'growth' according to the definition during the study period were associated with a higher risk of requiring surgery (HR 14.6 [95\% CI 3.4-62.6], $P<0.001$ ).

On univariate analysis, factors associated with growth were: tumors causing new neurological symptoms (HR 4.1 [95\% CI 1.2-13.7], $P=0.022)$, and larger tumor volume at diagnosis (HR 1.2 [95\% CI 1.0-1.5], $P=0.030$ ). Increased age at diagnosis was associated with reduced risk of growth (HR 0.95 [95\% CI 0.9-1.0], $P=0.044$ ). Factors associated

with surgery were a symptomatic presentation (HR 8.1,95\% CI [2.2-29.5], $P=0.002$ ), T2 hyperintensity (HR 3.6 [95\% CI 1.4-9.3], $P=0.007$ ), meeting the growth definition (HR 55.1 [95\% CI 10.7-282.9], $P<0.001$ ), and increased tumor volume (HR 1.1 [95\% CI 1.0-1.1], $P=0.041$ ). There were no factors identified that were significantly associated with progression after surgery or development of multiple meningioma. On multivariate analysis, large meningioma volume remained a significant factor for meningioma growth (HR 1.2 [95\% CI 1.0-1.5], $P=0.039$ ).

\section{Overall patient outcomes}

The majority of patients were alive at the end of the study period $(96.3 \%, \mathrm{n}=52 / 54)$. One patient died due to a myocardial infarction whilst under follow up, and the other patient 
Table 2 Table of growth definitions used in meningioma studies, with percentage of RIM meeting each definition

\begin{tabular}{|c|c|c|c|c|}
\hline Author and year & Growth definition & Population studied & $\begin{array}{l}\% \text { of meningiomas that met } \\
\text { the study-specific growth } \\
\text { definition (n/total) }\end{array}$ & $\begin{array}{l}\% \text { of RIM in our study that } \\
\text { met growth definition }(\mathrm{n} / \\
\text { total) }\end{array}$ \\
\hline Islim et al. 2020* [19] & $\begin{aligned} \mathrm{AGR} & \geq 2 \mathrm{~cm}^{3} / \text { year or } \\
\mathrm{AGR} & \geq 1 \mathrm{~cm}^{3} / \text { year and } \\
\mathrm{RGR} & \geq 30 \% / \text { year }\end{aligned}$ & Incidental meningioma & $7.5 \%(29 / 385)$ & $39.7 \%(29 / 73)$ \\
\hline Materi et al. 2020 [21] & AGR $>1.28 \mathrm{~cm}^{3} /$ year & $\begin{array}{l}\text { Sub-totally resected menin- } \\
\text { gioma }\end{array}$ & NA & $35.6 \%(26 / 73)$ \\
\hline Behbahani et al. 2019 [22] & $\begin{array}{l}\text { Volume increase }>15 \% \\
\text { Volume increase }>8.2 \%\end{array}$ & Incidental meningioma & $\begin{array}{l}70.6 \%(72 / 102) \\
79.4 \%(81 / 102)\end{array}$ & $\begin{array}{l}95.9 \%(70 / 73) \\
97.3 \%(71 / 73)\end{array}$ \\
\hline Lee et al. 2017 [23] & $\mathrm{AGR} \geq 2 \mathrm{~cm}^{3} /$ year & $\begin{array}{l}\text { Untreated meningioma (inci- } \\
\text { dental and symptomatic) }\end{array}$ & $25.4 \%(59 / 232)$ & $28.7 \%(21 / 73)$ \\
\hline Lee et al. $2017 *[24]$ & $\begin{array}{l}\text { AGR } \geq 2 \mathrm{~cm}^{3} / \text { year or } \\
\text { AGR } \geq 1 \mathrm{~cm}^{3} / \text { year and } \\
\mathrm{RGR} \geq 30 \% / \text { year }\end{array}$ & $\begin{array}{l}\text { Untreated meningioma (inci- } \\
\text { dental and symptomatic) }\end{array}$ & $29.7 \%(69 / 232)$ & $39.7 \%(29 / 73)$ \\
\hline Hunter et al. 2017 [25] & Volume increase $>20 \%$ & $\begin{array}{l}\text { Sub-totally resected petro- } \\
\text { clival meningioma }\end{array}$ & $66.7 \%(15 / 23)$ & $94.5 \%(69 / 73)$ \\
\hline Hashimoto et al. 2012 [26] & Volume increase $>15 \%$ & Incidental meningioma & $62.8 \%(71 / 113)$ & $95.9 \%(70 / 73)$ \\
\hline Nakasu et al. 2011 [27] & Volume increase $>8.2 \%$ & $\begin{array}{l}\text { Incidental and residual/ } \\
\text { recurrent meningioma }\end{array}$ & $84.6 \%(44 / 52)$ & $97.3 \%(71 / 73)$ \\
\hline Oya et al. 2011 [28] & Volume increase $>8.2 \%$ & $\begin{array}{l}\text { Untreated meningioma (inci- } \\
\text { dental and symptomatic) }\end{array}$ & $44 \%(120 / 273)$ & $97.3 \%(71 / 73)$ \\
\hline Hashiba et al. 2009 [29] & Volume increase $>15 \%$ & Incidental meningioma & $62.9 \%(44 / 70)$ & $95.9 \%(70 / 73)$ \\
\hline Other criteria: & $\begin{array}{l}20 \% \text { change per year } \\
33 \% \text { change per year } \\
\geq 1 \mathrm{~cm}^{3} \text { per year }\end{array}$ & & & $\begin{array}{l}80.8 \%(59 / 73) \\
68.5 \%(50 / 73) \\
38.4 \%(28 / 73)\end{array}$ \\
\hline
\end{tabular}

$A G R$ absolute growth rate, $R G R$ relative growth rate

*Studies which used the same meningioma growth definition

had an existing diagnosis of recurrent hemangioblastoma that was being managed palliatively at the time of RIM discovery. Half of the study cohort had multiple meningiomas by the end of the study period or at 5 years after diagnosis $(50 \%, \mathrm{n}=27 / 54)$. Two patients developed 8 new RIM during the study period.

\section{Discussion}

In this study, we highlight that on long-term follow up, RIM demonstrate high absolute and relative growth rates. Symptomatic presentation and large volume tumors were associated with higher rates of tumor growth. Radiation induced meningioma exhibited a high rate of early recurrence after surgical resection compared to sporadic meningioma [30].

This cohort of RIM patients appears to have less of a female predominance than sporadic meningioma [31]. This is congruent with previous knowledge $[10,32]$, and it has been suggested that males have an excess risk of developing RIM, due to increased susceptibility to NF2 rearrangements after radiation treatment [33, 34].

The finding that half patients develop multiple RIMs over the course of their lifetime is in contrast to recent studies that reported lower rates $(11.9-15.8 \%)[1,10]$. The propensity to develop new meningiomas warrants the need for longterm follow-up and more frequent interval imaging (e.g. 6 monthly) may be required [35]. Our recurrence rate (41.0\%) after surgery is higher than the published literature (18.3\%) [36], as is the proportion of RIMs with a WHO grade 2 histology $(43.6 \%)[1,37]$.

Due to the small number of patients undergoing stereotactic radiosurgery (SRS) and fractionated radiation therapy (fRT) in our series, the benefit of SRS and further fRT remains unclear. A recent study investigating the use of SRS in RIM concluded that SRS may be effective in WHO grade 1 or incidentally diagnosed radiation induced meningiomas $[38,39]$, however it is worth noting that lower volume RIM in our cohort were less likely to grow, and therefore treatment response to SRS may be overstated.

Two previous studies have defined a fast-growing nonradiation induced meningioma as one which demonstrates an AGR $\geq 2 \mathrm{~cm}^{3} /$ year or AGR $\geq 1 \mathrm{~cm}^{3} /$ year and $\mathrm{RGR} \geq 30 \% /$ year. These were a study of 441 incidental meningiomas discovered over a similar time frame in our center, and a study of 232 untreated incidental and symptomatic meningiomas. The results of these two studies, which utilised two different methods of volume measurement; $\mathrm{ABC} / 2$ and 


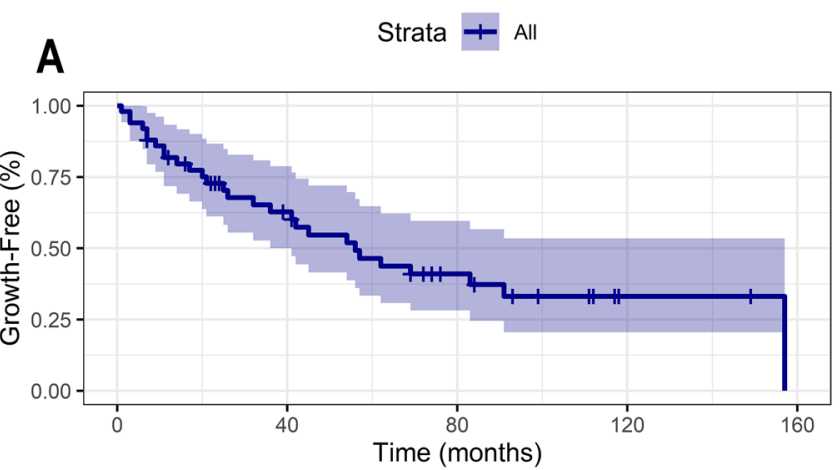

Number at risk
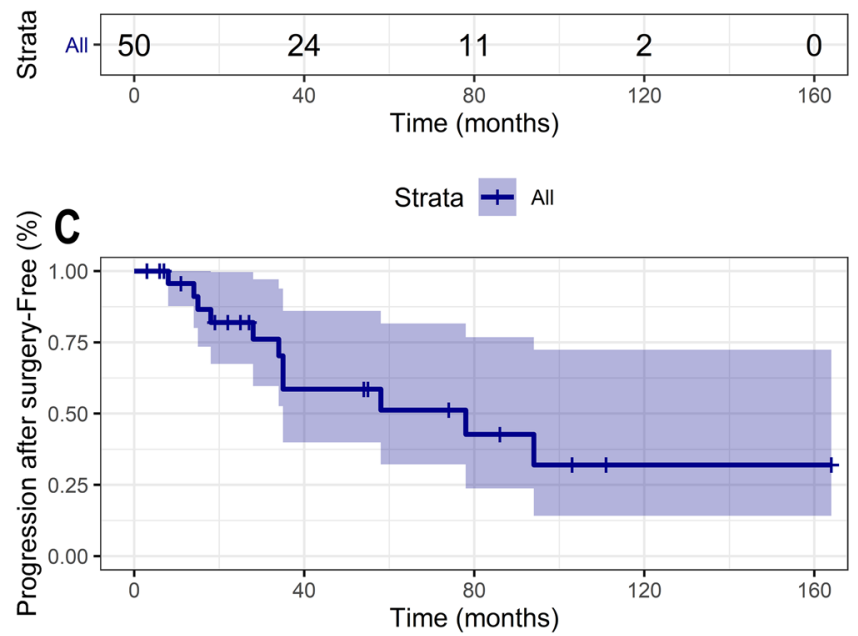

Number at risk

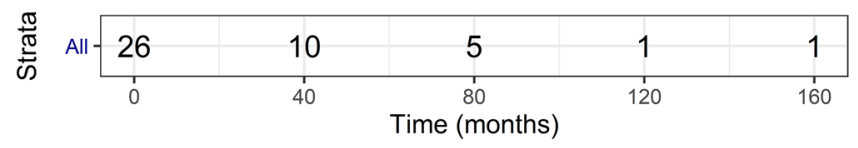

B Strata + All

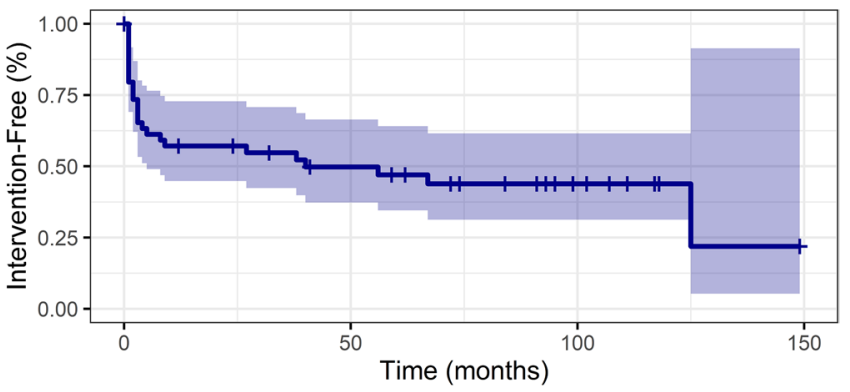

Number at risk
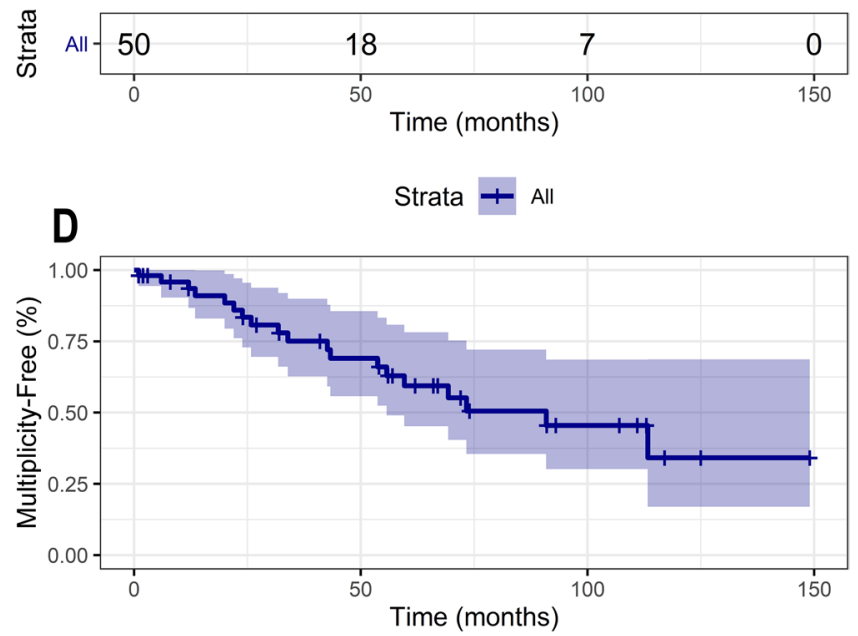

Number at risk

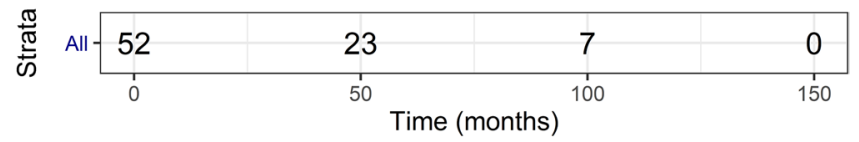

Fig. 3 Kaplan Meier curves demonstrating Kaplan Meier curves demonstrating. a Growth-Free survival, b intervention-free survival, c progression-free survival after surgery, and $\mathbf{d}$ multiple-free survival in RIM patients

manual segmentation, both demonstrated a lower risk of sporadic meningioma growth in comparison to RIMs (7.5\% and $29.7 \%$ vs $39.7 \%$ ) (Table 2), supplementing the conclusion of RIMs being clinically aggressive meningiomas. These findings also serve to highlight the need for standardized growth definitions in meningioma. Investigators use a variety of definitions to define growth. In order to effectively determine what constitutes meningioma 'growth', uniform criteria need to be established to validate volumetric study findings. The Response Assessment in Neuro-Oncology (RANO) working group recently emphasized the need to consider time interval, size and imaging modality as variables in assessing meningioma growth, and proposed a fastgrowing meningioma as one that has demonstrated a $>15 \%$ increase in bidimensional enhancing product in the previous 6 months [40]. These criteria remain to be validated in both sporadic and radiation induced meningiomas.
It has been suggested that RIM tumorigenesis occurs through different mechanisms than sporadic meningioma [41]. NF2 mutations have been reported to occur less frequently in RIMs (6\% vs 30-50\%), and other druggable targets found in sporadic meningioma (SMO, TRAF7, KLF4, PIK3CA and ATK1) are often absent in RIMs [33, 42]. Certain copy number alterations (CNAs) have been observed almost universally in RIM, such as combined loss of heterozygosity on chromosome $1 \mathrm{p}$ and $22 \mathrm{q}$, which is less commonly encountered in benign meningioma [43, 44]. This supports the hypothesis that radiation triggers genome structural rearrangements through error prone repair of double strand DNA breaks, which may lead to non-homologous end joining and increased growth potential. It is postulated that craniospinal radiation may also lead to NF2 intronic rearrangements/fusion events (found in $39 \%$ RIM vs $0 \%$ sporadic meningioma) as opposed to 
mutations seen in sporadic meningioma, subsequently leading to inactivation.

Our clinical findings correlate with these factors and indicate that RIM appears to be a distinct molecular entity with unique growth properties, and the drivers behind this need to be investigated by molecular studies in future work.

Harrison et al. classified RIMs into three groups based on amount of radiation administered, with low dose defined as $<10$ Gy, moderate dose 10-20 Gy, and high dose $>20$ Gy [45]. The vast majority of our cases represent RIMs that occurred as a result of high dose RT. In comparison to those due to low dose RT (for historical treatments such as tinea capitis), RIMs arising from high dose RT tend to exhibit a shorter latency period, a more even male to female ratio, and increased recurrence after surgery [36, 45-47].

\section{Study strengths}

To our knowledge, this is the first study to analyse the volumetric growth rates of RIM and their natural history, the first to examine volumetric growth rates immediately after tumor discovery, and the potential prognostic factors for growth, surgery, progression, and development of multiple RIM. Furthermore, our cohort of RIMs was diagnosed between 2007 and 2019 and represents a more recent case-series with a median follow up period of 6 years.

\section{Study limitations}

There are several limitations to our study. First, the study was retrospective in design and not all tumor volumes were available to be comprehensively measured during the study period, and the regression analyses were limited to tumors that underwent more than one follow-up MRI scan. Second, volumetric analysis was commenced upon tumor discovery, and therefore it is not possible to delineate for how long the tumor was present before being discovered, in addition to its growth rate before discovery. There was therefore no standardized diagnostic start point for the study. Third, the use of intervention as a study endpoint was limited by clinician and patient biases and might have impacted the results of the study. The tumor board in our center considers the clinical and radiological status of the meningioma, patient comorbidities and performance status before discussion of the recommended and alternate management strategies with the patient to reach a shared-care decision. Due to the retrospective nature of the study, we were unable to assess the reasons behind continued monitoring in cases of symptomatic progression. Nonetheless, it is reasonable that this was due to patient preference, personal and social circumstances, loss of driving license for at least 6 months in the UK and risks of unemployment, post-surgical epilepsy, new neurological deficit and death. Fourth, due to lack of screening for late effects of cranial irradiation in our center, patients with more indolent RIMs may have not been detected clinically, and thus our cohort may consist of more clinically aggressive RIMs than if all childhood cancer survivors were systematically screened. Fifth, assessment of whether the meningioma occurred within the radiation field or not was not feasible. This was due to the inability to access the planning scans for patients who mostly underwent intracranial radiation between 1970 and 1990 . Nonetheless, radiation techniques at the time were mostly whole brain radiotherapy and two-dimensional conformal radiotherapy, which is associated with out of field spillage [48]. Therefore, it's likely that patients in this study are a true representative of RIMs. Additionally, due to the historic nature of radiation details, number of fractions and total radiation dose were missing for more than a third of patients. Finally, in this study, we used an approximated method of measuring tumor volume $(\mathrm{ABC} / 2)$, however this has been externally validated to be a reliable method of measuring tumor volume in meningiomas $[49,50]$.

\section{Conclusions}

Radiation induced meningioma is a less commonly reported, but increasing clinical problem with no clear consensus on the optimal management strategy. RIM are more likely to be symptomatic, require surgical resection, have grade 2 histology, and progress compared to sporadic meningioma. They exhibit high absolute and relative growth, and thus appear to be more likely to develop clinical and radiological progression following discovery.

Supplementary Information The online version contains supplementary material available at https://doi.org/10.1007/s11060-021-03761-3.

Acknowledgements CSG and BAT are supported by a Grant from the Wolfson Foundation.

Author contributions Conception and design: CSG, AII, MDJ. Data collection: CSG, AII, BAT. Data analysis: CSG, AII, BAT, CPM, MDJ. Data interpretation: CSG, AII, BAT, CPM, SK, NR, SM, BH, NT, CEG, DL, SM, EC, AB, MDJ. Manuscript drafting: CSG, AII. Manuscript review, revision and completion: CSG, AII, BAT, CPM, SK, NR, SM, BH, NT, CEG, DL, SM, EC, AB, MDJ.

Funding The authors did not receive any external funding for the completion of this study. CSG and BAT are supported by a grant from the Wolfson Foundation.

Data availability Anonymized data are available (upon reasonable request) from the corresponding author. 


\section{Declarations}

Conflict of interest No conflicts of interest to declare.

Ethical approval The study was approved by the hospital audit committee prior to commencement of the study.

Open Access This article is licensed under a Creative Commons Attribution 4.0 International License, which permits use, sharing, adaptation, distribution and reproduction in any medium or format, as long as you give appropriate credit to the original author(s) and the source, provide a link to the Creative Commons licence, and indicate if changes were made. The images or other third party material in this article are included in the article's Creative Commons licence, unless indicated otherwise in a credit line to the material. If material is not included in the article's Creative Commons licence and your intended use is not permitted by statutory regulation or exceeds the permitted use, you will need to obtain permission directly from the copyright holder. To view a copy of this licence, visit http://creativecommons.org/licenses/by/4.0/.

\section{References}

1. Godlewski B, Drummond KJ, Kaye AH (2012) Radiation-induced meningiomas after high-dose cranial irradiation. J Clin Neurosci 19:1627-1635. https://doi.org/10.1016/j.jocn.2012.05.011

2. Ossama A-M, Cahide T, Svetlana P, Jeffrey RS, Michael JH (2004) Radiation-induced meningiomas: clinical, pathological, cytokinetic, and cytogenetic characteristics. J Neurosurg 100:1002-1013. https://doi.org/10.3171/jns.2004.100.6.1002

3. Shenoy SN, Munish KG, Raja A (2004) High dose radiation induced meningioma. Br J Neurosurg 18:617-621. https://doi. org/10.1080/02688690400022789

4. Michael JH, David EW, Tai-Shing L, Robin JM, Ved PS (1991) Radiation-induced meningiomas: experience at the Mount Sinai Hospital and review of the literature. J Neurosurg 75:564-574. https://doi.org/10.3171/jns.1991.75.4.0564

5. Galloway TJ, Indelicato DJ, Amdur RJ, Swanson EL, Morris CG, Marcus RB (2011) Favorable outcomes of pediatric patients treated with radiotherapy to the central nervous system who develop radiation-induced meningiomas. Int J Radiat Oncol Biol Phys 79:117-120. https://doi.org/10.1016/j.ijrobp.2009.10.045

6. Vinchon M, Leblond P, Caron S, Delestret I, Baroncini M, Coche B (2011) Radiation-induced tumors in children irradiated for brain tumor: a longitudinal study. Childs Nerv Syst 27:445-453. https:// doi.org/10.1007/s00381-011-1390-4

7. Remes TM, Suo-Palosaari MH, Heikkilä VP, Sutela AK, Koskenkorva PKT, Toiviainen-Salo SM, Porra L, Arikoski PM, Lähteenmäki PM, Pokka TM, Arola MO, Riikonen VP, Sirkiä KH, Lönnqvist TRI, Rantala HMJ, Ojaniemi MK, Harila-Saari AH (2019) Radiation-induced meningiomas after childhood brain tumor: a magnetic resonance imaging screening study. J Adolesc Young Adult Oncol 8:593-601. https://doi.org/10.1089/jayao.2019.0010

8. Kok JL, Teepen JC, van Leeuwen FE, Tissing WJE, Neggers S, van der Pal HJ, Loonen JJ, Bresters D, Versluys B, van den Heuvel-Eibrink MM, van Dulmen-den Broeder E, van der Heiden-van der Loo M, Aleman BMP, Daniels LA, Haasbeek CJA, Hoeben B, Janssens GO, Maduro JH, Oldenburger F, van Rij C, Tersteeg R, Hauptmann M, Kremer LCM, Ronckers CM (2019) Risk of benign meningioma after childhood cancer in the DCOG-LATER cohort: contributions of radiation dose, exposed cranial volume, and age. Neuro Oncol 21:392-403. https://doi.org/10.1093/neuonc/noy 124
9. Banerjee J, Pääkkö E, Harila M, Herva R, Tuominen J, Koivula A, Lanning M, Harila-Saari A (2009) Radiation-induced meningiomas: a shadow in the success story of childhood leukemia. Neuro Oncol 11:543-549. https://doi.org/10.1215/15228517-2008-122

10. Yamanaka R, Hayano A, Kanayama T (2017) Radiation-induced meningiomas: an exhaustive review of the literature. World Neurosurg 97:635-644.e638. https://doi.org/10.1016/j.wneu.2016.09. 094

11. Verbruggen LC, Hudson MM, Bowers DC, Ronckers CM, Armstrong GT, Skinner R, Hoving EW, Janssens GO, van der Pal HJH, Kremer LCM, Mulder RL (2020) Variations in screening and management practices for subsequent asymptomatic meningiomas in childhood, adolescent and young adult cancer survivors. J Neurooncol 147:417-425. https://doi.org/10.1007/ s11060-020-03436-5

12. Co JL, Swain M, Murray LJ, Ahmed S, Laperriere NJ, Tsang DS, Yu E, Pintilie M, Weiss J, Hodgson DC (2019) Meningioma screening with mri in childhood leukemia survivors treated with cranial radiation. Int J Radiat Oncol Biol Phys 104:640-643. https://doi.org/10.1016/j.ijrobp.2019.02.057

13. Nakasu S, Fukami T, Jito J, Nozaki K (2009) Recurrence and regrowth of benign meningiomas. Brain Tumor Pathol 26:6972. https://doi.org/10.1007/s10014-009-0251-2

14. Nakamura M, Roser F, Michel J, Jacobs C, Samii M (2005) Volumetric analysis of the growth rate of incompletely resected intracranial meningiomas. Zent Neurochir 66:17-23. https://doi. org/10.1055/s-2004-836225

15. Jääskeläinen $\mathrm{J}$, Haltia $\mathrm{M}$, Laasonen $\mathrm{E}$, Wahlström $\mathrm{T}$, Valtonen $S$ (1985) The growth rate of intracranial meningiomas and its relation to histology. An analysis of 43 patients. Surg Neurol 24:165-172. https://doi.org/10.1016/0090-3019(85)90180-6

16. Nakasu S, Fukami T, Nakajima M, Watanabe K, Ichikawa M, Matsuda M (2005) Growth pattern changes of meningiomas: long-term analysis. Neurosurgery 56:946-955 (discussion 946-955)

17. Fountain DM, Soon WC, Matys T, Guilfoyle MR, Kirollos R, Santarius T (2017) Volumetric growth rates of meningioma and its correlation with histological diagnosis and clinical outcome: a systematic review. Acta Neurochir (Wien) 159:435-445. https:// doi.org/10.1007/s00701-016-3071-2

18. Islim AI, Mohan M, Moon RDC, Srikandarajah N, Mills SJ, Brodbelt AR, Jenkinson MD (2019) Incidental intracranial meningiomas: a systematic review and meta-analysis of prognostic factors and outcomes. J Neurooncol 142:211-221. https://doi.org/ 10.1007/s11060-019-03104-3

19. Islim AI, Kolamunnage-Dona R, Mohan M, Moon RDC, Crofton A, Haylock BJ, Rathi N, Brodbelt AR, Mills SJ, Jenkinson MD (2020) A prognostic model to personalize monitoring regimes for patients with incidental asymptomatic meningiomas. Neuro Oncol 22:278-289. https://doi.org/10.1093/neuonc/noz160

20. Bland JM, Altman DG (1997) Statistics notes: Cronbach's alpha. BMJ 314:572. https://doi.org/10.1136/bmj.314.7080.572

21. Materi J, Mampre D, Ehresman J, Rincon-Torroella J, Chaichana KL (2020) Predictors of recurrence and high growth rate of residual meningiomas after subtotal resection. J Neurosurg. https://doi. org/10.3171/2019.10.Jns192466

22. Behbahani M, Skeie GO, Eide GE, Hausken A, Lund-Johansen M, Skeie BS (2019) A prospective study of the natural history of incidental meningioma-hold your horses! Neurooncol Pract 6:438-450. https://doi.org/10.1093/nop/npz011

23. Eun Jung L, Jeong Hoon K, Eun Suk P, Young-Hoon K, Jae Koo L, Seok Ho H, Young Hyun C, Chang Jin K (2017) A novel weighted scoring system for estimating the risk of rapid growth in untreated intracranial meningiomas. J Neurosurg JNS 127:971980. https://doi.org/10.3171/2016.9.JNS161669 
24. Lee EJ, Park JH, Park ES, Kim JH (2017) "Wait-and-see" strategies for newly diagnosed intracranial meningiomas based on the risk of future observation failure. World Neurosurg 107:604-611. https://doi.org/10.1016/j.wneu.2017.08.060

25. Hunter JB, O'Connell BP, Carlson ML, Chambless LC, Yawn RJ, Wang R, Mistry A, Thompson RC, Weaver KD, Wanna GB (2018) Tumor progression following petroclival meningioma subtotal resection: a volumetric study. Oper Neurosurg (Hagerstown) 14:215-223. https://doi.org/10.1093/ons/opx098

26. Hashimoto N, Rabo CS, Okita Y, Kinoshita M, Kagawa N, Fujimoto Y, Morii E, Kishima H, Maruno M, Kato A, Yoshimine T (2012) Slower growth of skull base meningiomas compared with non-skull base meningiomas based on volumetric and biological studies. J Neurosurg 116:574-580. https://doi.org/10.3171/2011. 11.Jns11999

27. Nakasu S, Nakasu Y, Fukami T, Jito J, Nozaki K (2011) Growth curve analysis of asymptomatic and symptomatic meningiomas. J Neurooncol 102:303-310. https://doi.org/10.1007/ s11060-010-0319-1

28. Oya S, Kim SH, Sade B, Lee JH (2011) The natural history of intracranial meningiomas. J Neurosurg 114:1250-1256. https:// doi.org/10.3171/2010.12.Jns101623

29. Hashiba T, Hashimoto N, Izumoto S, Suzuki T, Kagawa N, Maruno M, Kato A, Yoshimine T (2009) Serial volumetric assessment of the natural history and growth pattern of incidentally discovered meningiomas. J Neurosurg 110:675-684. https://doi. org/10.3171/2008.8.Jns08481

30. Gallagher MJ, Jenkinson MD, Brodbelt AR, Mills SJ, Chavredakis E (2016) WHO grade 1 meningioma recurrence: are location and Simpson grade still relevant? Clin Neurol Neurosurg 141:117121. https://doi.org/10.1016/j.clineuro.2016.01.006

31. Wiemels J, Wrensch M, Claus EB (2010) Epidemiology and etiology of meningioma. J Neurooncol 99:307-314. https://doi.org/10. 1007/s11060-010-0386-3

32. Felix U, Yigal S, Guy R, Shifra F, Sergey S (2008) Radiationinduced meningioma. Neurosurg Focus FOC 24:E7. https://doi. org/10.3171/FOC/2008/24/5/E7

33. Agnihotri S, Suppiah S, Tonge PD, Jalali S, Danesh A, Bruce JP, Mamatjan Y, Klironomos G, Gonen L, Au K, Mansouri S, Karimi S, Sahm F, von Deimling A, Taylor MD, Laperriere NJ, Pugh TJ, Aldape KD, Zadeh G (2017) Therapeutic radiation for childhood cancer drives structural aberrations of NF2 in meningiomas. Nat Commun 8:186. https://doi.org/10.1038/s41467-017-00174-7

34. Preston DL, Ron E, Yonehara S, Kobuke T, Fujii H, Kishikawa M, Tokunaga M, Tokuoka S, Mabuchi K (2002) Tumors of the nervous sy-stem and pituitary gland associated with atomic bomb radiation exposure. JNCI: J Natl Cancer Inst 94:1555-1563. https:// doi.org/10.1093/jnci/94.20.1555

35. Tsermoulas G, Turel MK, Wilcox JT, Shultz D, Farb R, Zadeh G, Bernstein M (2018) Management of multiple meningiomas. J Neurosurg 128:1403-1409. https://doi.org/10.3171/2017.2.Jns16 2608

36. Sadetzki S, Flint-Richter P, Ben-Tal T, Nass D (2002) Radiationinduced meningioma: a descriptive study of 253 cases. J Neurosurg 97:1078-1082. https://doi.org/10.3171/jns.2002.97.5.1078

37. Champeaux C, Wilson E, Shieff C, Khan AA, Thorne L (2016) WHO grade II meningioma: a retrospective study for outcome and prognostic factor assessment. J Neurooncol 129:337-345. https:// doi.org/10.1007/s11060-016-2181-2

38. Huo M, Laperriere N, van Prooijen M, Shultz D, Coolens C, Hodaie M, Cusimano M, Gentili F, Zadeh G, Payne D, Schwartz M, Tsang DS (2020) Efficacy of stereotactic radiosurgery for radiation-induced meningiomas. J Neurooncol 148:299-305. https://doi.org/10.1007/s11060-020-03515-7

39. Kondziolka D, Kano H, Kanaan H, Madhok R, Mathieu D, Flickinger JC, Lunsford LD (2009) Stereotactic radiosurgery for radiation-induced meningiomas. Neurosurgery 64:463-469. https://doi. org/10.1227/01.Neu.0000336765.85922.D9 (discussion 469-470)

40. Huang RY, Bi WL, Weller M, Kaley T, Blakeley J, Dunn I, Galanis E, Preusser M, McDermott M, Rogers L, Raizer J, Schiff D, Soffietti R, Tonn J-C, Vogelbaum M, Weber D, Reardon DA, Wen PY (2019) Proposed response assessment and endpoints for meningioma clinical trials: report from the Response Assessment in Neuro-Oncology Working Group. Neuro Oncol 21:26-36. https://doi.org/10.1093/neuonc/noy 137

41. Al-Mefty O, Topsakal C, Pravdenkova S, Sawyer JR, Harrison MJ (2004) Radiation-induced meningiomas: clinical, pathological, cytokinetic, and cytogenetic characteristics. J Neurosurg 100:1002-1013. https://doi.org/10.3171/jns.2004.100.6.1002

42. Shoshan Y, Chernova O, Juen SS, Somerville RP, Israel Z, Barnett GH, Cowell JK (2000) Radiation-induced meningioma: a distinct molecular genetic pattern? J Neuropathol Exp Neurol 59:614-620. https://doi.org/10.1093/jnen/59.7.614

43. Kim JH, Lee SH, Rhee CH, Park SY, Lee JH (1998) Loss of heterozygosity on chromosome $22 \mathrm{q}$ and $17 \mathrm{p}$ correlates with aggressiveness of meningiomas. J Neurooncol 40:101-106. https://doi. org/10.1023/a:1006110812240

44. Miller R Jr, DeCandio ML, Dixon-Mah Y, Giglio P, Vandergrift WA 3rd, Banik NL, Patel SJ, Varma AK, Das A (2014) Molecular targets and treatment of meningioma. J Neurol Neurosurg $1: 1000101$

45. Harrison MJ, Wolfe DE, Lau TS, Mitnick RJ, Sachdev VP (1991) Radiation-induced meningiomas: experience at the Mount Sinai Hospital and review of the literature. J Neurosurg 75:564-574. https://doi.org/10.3171/jns.1991.75.4.0564

46. Pollak L, Walach N, Gur R, Schiffer J (1998) Meningiomas after radiotherapy for tinea capitis-still no history. Tumori 84:65-68

47. Salvati M, Cervoni L, Puzzilli F, Bristot R, Delfini R, Gagliardi FM (1997) High-dose radiation-induced meningiomas. Surg Neurol 47:435-441. https://doi.org/10.1016/s0090-3019(96)00360-6 (discussion 441-432)

48. Teh BS, Mai WY, Grant WH 3rd, Chiu JK, Lu HH, Carpenter LS, Woo SY, Butler EB (2002) Intensity modulated radiotherapy (IMRT) decreases treatment-related morbidity and potentially enhances tumor control. Cancer Invest 20:437-451. https://doi. org/10.1081/cnv-120002143

49. Ishi Y, Terasaka S, Yamaguchi S, Yoshida M, Endo S, Kobayashi H, Houkin K (2016) Reliability of the size evaluation method for meningiomas: maximum diameter, $\mathrm{ABC} / 2$ formula, and planimetry method. World Neurosurg 94:80-88. https://doi.org/10. 1016/j.wneu.2016.06.108

50. Opalak CF, Parry M, Rock AK, Sima AP, Carr MT, Chandra V, Workman KG, Somasundaram A, Broaddus WC (2019) Comparison of $\mathrm{ABC} / 2$ estimation and a volumetric computerized method for measurement of meningiomas using magnetic resonance imaging. J Neurooncol 144:275-282. https://doi.org/10.1007/ s11060-019-03205-z

Publisher's Note Springer Nature remains neutral with regard to jurisdictional claims in published maps and institutional affiliations. 